\title{
Una exploración de interés, ahorro e inversión estudiando una muestra
} poblacional de Honduras

\section{An exploration of interest, savings and investment studying a population sample of Honduras}

Hypatia Vanessa Saravia Jiménez ${ }^{1}$

\begin{abstract}
Resumen:A continuación, se muestra una exploración de personas de diferentes edades en Honduras. Y se analiza los conocimientos en educación financieras que estas personas poseen tomando como premisa la famosa frase de Pitágoras, "Educa a los niños y no será necesario castigar a los hombres". Si esto es cierto, los niños educados correctamente serán personas de bien para la sociedad y un país en general. Y educar financieramente creará familias y naciones prosperas económicamente. Pero ¿Cómo utilizan actualmente los hondureños su dinero? ¿Cuáles son las principales áreas donde hay que poner especial atención para trabajar la educación financiera de los niños y universitarios hondureños? ¿Cómo está afectando la poca educación financiera que se imparte en la población a la familia hondureña y en el país?
\end{abstract}

Palabras-clave: Educación financieras. Matemáticas. Economia

Abstract: Below is an exploration of people of different ages in Honduras. And it analyzes the knowledge in financial education that these people possess taking as premise the famous phrase of Pythagoras, "Educates children and will not be necessary to punish men". If this is true, properly educated children will be good people for society and a country in general. And educating financially will create economically prosperous families and nations. But how do Hondurans currently use their money? What are the main areas where we must pay special attention to work on the financial education of Honduran children and university students? How is the little financial education that is given in the population to the Honduran family and in the country?

Key words: Financial education. Maths. Economy

\section{Desarrollo}

Siempre se ha pensado que las instituciones educativas son las encargadas de formar, como su nombre lo dice, educar a los estudiantes, y esto es cierto, pero cuando se habla de educación financiera, es importante un acompañamiento y respaldo del tema en casa. Los niños son como pequeñas esponjitas que aprenden todo del entorno que los rodean, por lo

\footnotetext{
${ }^{1}$ Doctora en Educación. Profesora en Universidad Nacional Autónoma de Honduras. E-mail: hypatiavsj@hotmail.com
}

Tangram - Revista de Educação Matemática, Dourados - MS - v.2 n. 1, pp. 58-66 (2018) 


\section{Una exploración de interés, ahorro e inversión estudiando una muestra poblacional de Honduras}

que, si están rodeados de padres consumidores, serán niños consumidores; padres ahorradores, serán niños ahorradores; padres emprendedores, serán niños emprendedores; o de padres que les enseñan correctamente como administrar su dinero, serán niños que administrarán correctamente los recursos, y esto ayudará a complementar lo aprendido en las instituciones educativas.

Según Jean Piaget los niños entre los 2 y los 7 años se encuentran en una etapa pre operacional, donde empiezan a relacionar símbolos y figuras. Por la razón anterior, basándose en esta observación, el Currículo Nacional de Pre básica en Honduras, se comienza a mostrarle los primeros números. Más adelante, el niño relaciona la matemática con el dinero, porque son las aplicaciones más comunes. Para explicar conceptos de adición y sustracciones se acostumbra comentar el famoso caso: si Juan tiene 10 lempiras (moneda nacional de Honduras), va a la pulpería (tienda de abarrotes) a comprar un dulce que cuesta 5 lempiras, después de la compra ¿Cuántos lempiras le quedan a Juan?

Pero estas aplicaciones no explican cómo administrar mejor el dinero, y no es esa la finalidad tampoco. En las escuelas, se enseña matemática, pero no es parte del currículo nacional dar educación financiera, a los niños, e incluso se imparten materias como contabilidad, entre otras que se ejemplifica como administrar una empresa, pero en el currículo nacional no hace mención a como administrar nuestros recursos personales, ni mucho menos como eliminar el miedo a los riesgos financieros. En base a las consideraciones anteriores, los hondureños saben de números e incluso llegan a la universidad y a sus trabajos sabiendo de álgebra, trigonometría, cálculo, pero carecen de habilidades para administrar correctamente el dinero.

Resultó oportuno hacer una pequeña investigación de una población de 40 estudiantes, se tomó como muestra 24 niños en edades comprendidas entre los 5 y 6 años de una institución pública de Honduras para explorar qué conocimientos básicos tienen de ahorro, interés e inversión. Sumado a esto, se encuestó a 21 estudiantes de diferentes carreras de la Facultad de Ciencias Económicas Administrativas y Contables de una Universidad, también pública, del Honduras y 6 docentes de la misma facultad y universidad.

\section{Resultados}

Se pudo observar los siguiente:

Tangram - Revista de Educação Matemática, Dourados - MS - v.2 n. 1, pp. 58 - 66 (2018) 


\section{Una exploración de interés, ahorro e inversión estudiando una muestra poblacional de Honduras}

La muestra tomada en niños se encuentra en una etapa pre operacional ${ }^{2}$, caracterizando a los niños con un alto grado de egocentrismo y como resultado dificultades para acceder a pensamientos con algún grado de abstracción. En esta etapa los niños aun no poseen la capacidad de seguir la lógica simple y hacer conclusiones validas de reflexiones concretas. Los niños en su mayoría reciben dinero como premio a su buena conducta, buenas calificaciones o buenas prácticas realizadas en el hogar, otros reciben dinero como regalo de parte de sus familiares por festividades de cumpleaños, navidad o día del niño. Pero, al no poseer responsabilidades mayores, no existe un objetivo concreto para ahorrar. Aun así, ahorran en su mayoría, por instrucciones de su entorno.

Los universitarios en su mayoría no ahorran, debido posiblemente a que tienen presupuestos ajustados. Los universitarios, al igual que los niños, tampoco poseen una motivación para ahorrar, ni poseen responsabilidades económicas. Entre otro factor que afecta para no ahorrar es que sus padres proveen y suplen los costos diarios a los que se enfrentan en el día a día y, de forma similar, así como los niños, no han desarrollado una conciencia del valor del dinero. Finalmente, otra razón para no ahorrar es porque los jóvenes universitarios están intentando encajar en un nuevo entorno social, destinando parte de su dinero en ropa, comida, útiles, videojuegos, etc. Para así poder tener mayor aceptación en ese ámbito social.

En cuanto a los docentes, hablando de ahorro, existe gran tendencia a realizarlo en forma disciplinada, tratando de alcanzar el $100 \%$. En la muestra estudiada, todos tienen responsabilidades económicas, casa propia, préstamos, educación de hijos, alimentación de la familia, entre otros gastos. También es importante resaltar que todos tienen conciencia del dinero, entre otras cosas, saben el valor del ahorro ya sea para emergencias o eventualidades, como también para poder hacer una inversión y no recurrir a préstamos con altas tasas de interés. Esto se puede tomar como una motivación.

\footnotetext{
2 Jean Piaget, en su Teoría del desarrollo cognitivo divide en 4 etapas principales el crecimiento físico como el desarrollo de un individuo, Estas etapas son: Sensomotriz, pre operacional, operaciones concretas y operaciones formales.
}

Tangram - Revista de Educação Matemática, Dourados - MS - v.2 n. 1, pp. 58 - 66 (2018) 


\section{Una exploración de interés, ahorro e inversión estudiando una muestra poblacional de Honduras}

Ahorro (porcentaje)

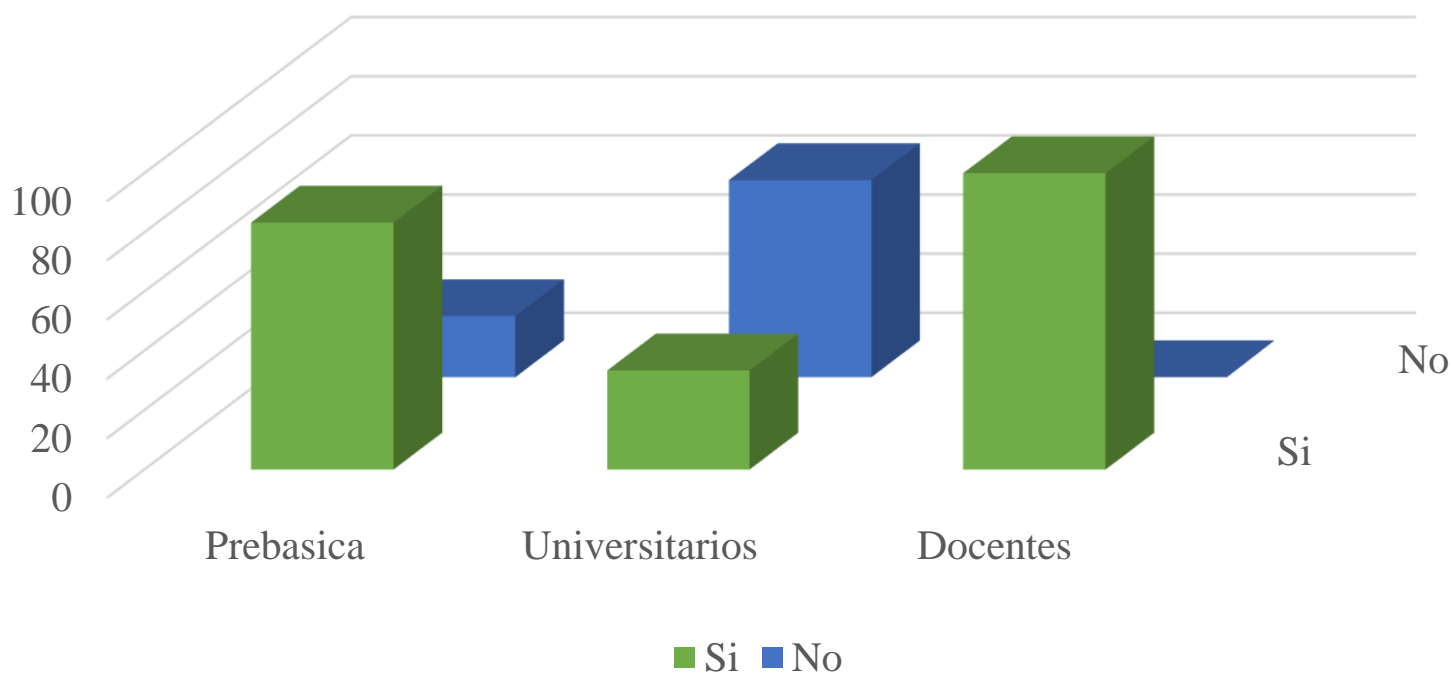

Figura 1 - Gráfico de ahorro

Fonte: Autoria própria

Cuando se habla de interés, los niños de pre básica prefieren obtener uno de sus juguetes favoritos el día de hoy, en lugar de dos de los mismos para el día siguiente. Curiosamente se dice que los niños viven el día a día, porque el ahorro es un plan a futuro, pero como antes se mencionó, lo hacen sin una motivación ni responsabilidad, es un acto de obediencia. Por lo que, como en los hogares, frecuentemente no se habla de interés o tasa de interés porque los niños no están muy empapados de estos términos y carecen de la capacidad para ahondar en ese tipo de conceptos abstractos.

A los universitarios y docentes se les efectuó la misma pregunta; qué prefieres, un depósito de5000 lempiras en una cuenta de ahorro al $20 \%$ de interés a tu favor o 5000 lempiras en una cuenta a plazo fijos al $40 \%$ de interés a tu favor. Ambos prefirieron las cuentas a plazo fijo con $40 \%$ de interés. Aunque esta pregunta no toma en cuenta la necesidad inmediata de la muestra, siempre se puede observar en el gráfico que el interés sigue siendo una prioridad para los participantes.

Tangram - Revista de Educação Matemática, Dourados - MS - v.2 n. 1, pp. 58 - 66 (2018) 


\section{Una exploración de interés, ahorro e inversión estudiando una muestra poblacional de Honduras}

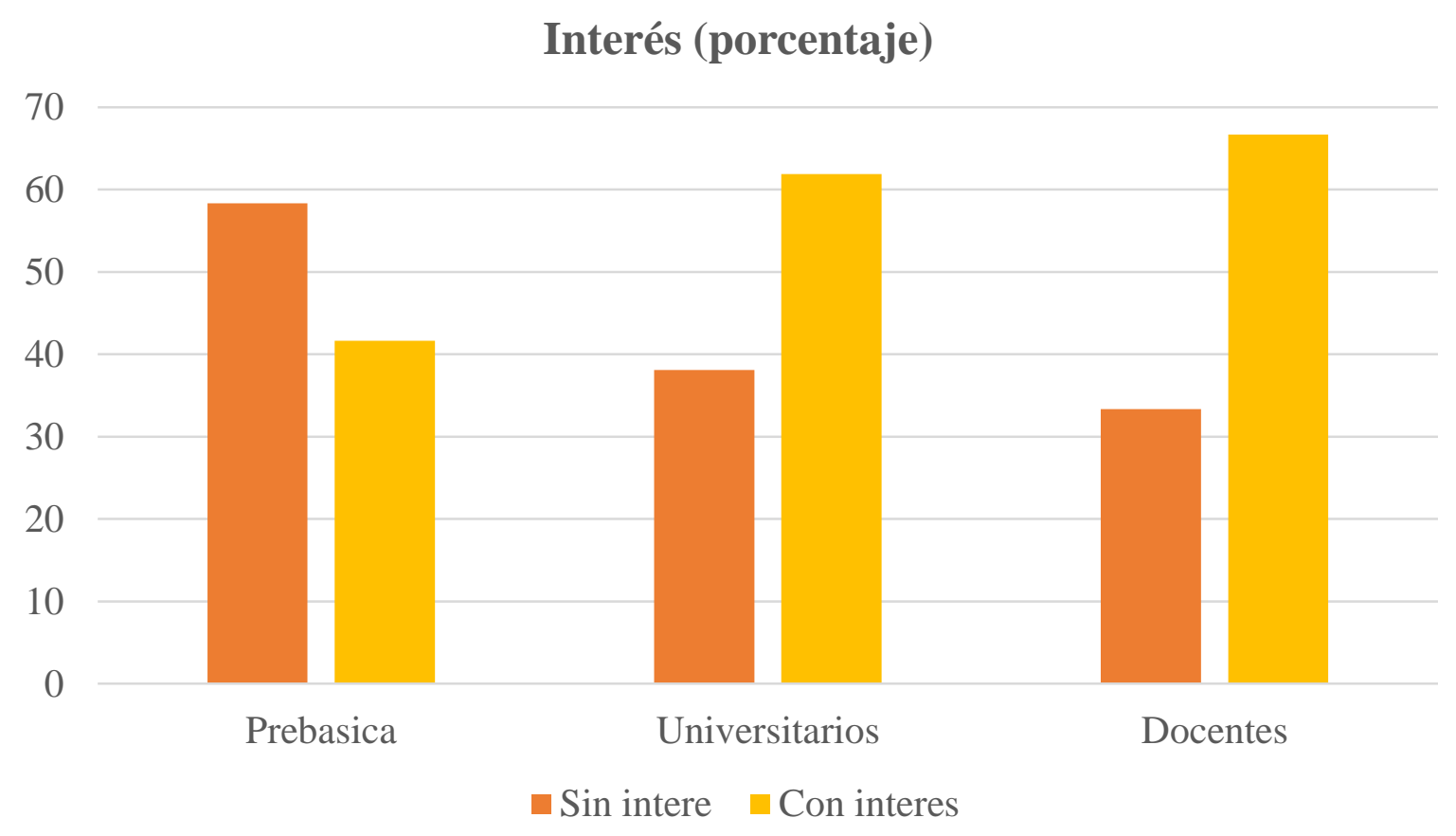

Figura 2 - Gráfico de interés

Fonte: Autoria própria

Finalmente, en cuanto a inversión se muestran tres diferentes gráficos En pre básica se preguntó si tuvieras mucho, mucho dinero, ¿qué harías con él? (no tiene noción de una cantidad específica). En el grafico la categoría de compras sobresale, luego hay dos categorías; ahorro y beneficencia, y curiosamente en ambas categorías aparecen los padres, esto se debe a que en ahorro algunos niños dijeron dárselo a sus papás para que lo guarden y se los regrese cuando esté grande. Y, en la categoría beneficencia, dijeron dárselo a sus padres para que paguen sus deudas.

A los universitarios y a los docentes se les hizo la misma pregunta, si te ganas un millón de dólares $(24,250,000$ de lempiras) ¿Qué harías con el dinero? Para los universitarios sobresale la categoría de Compras y pagos, luego beneficencia e inversión (que no está en los niños), tienen niveles de importancia similares, y ahorro no tiene relevancia en el gráfico. Para los docentes, el grafico de es muy parecido al de los

Tangram - Revista de Educação Matemática, Dourados - MS - v.2 n. 1, pp. 58 - 66 (2018) 
Una exploración de interés, ahorro e inversión estudiando una muestra poblacional de Honduras

universitarios a diferencia que los ahorros tienen casi igual importancia que la inversión y la beneficencia disminuye.

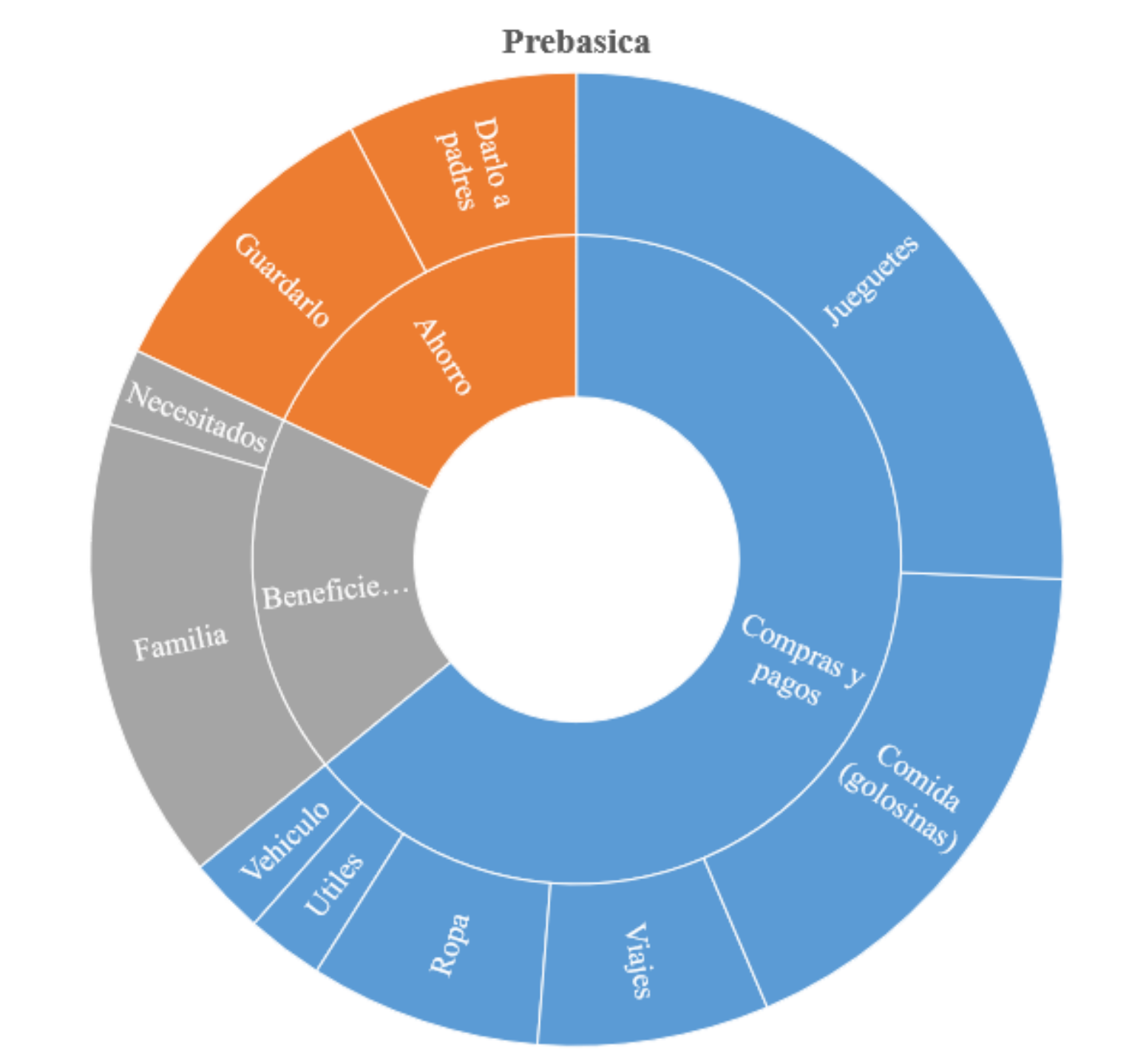

Figura 3 - Prebásica

Fonte: Autoria própria

Tangram - Revista de Educação Matemática, Dourados - MS - v.2 n. 1, pp. 58 - 66 (2018) 
Una exploración de interés, ahorro e inversión estudiando una muestra poblacional de Honduras

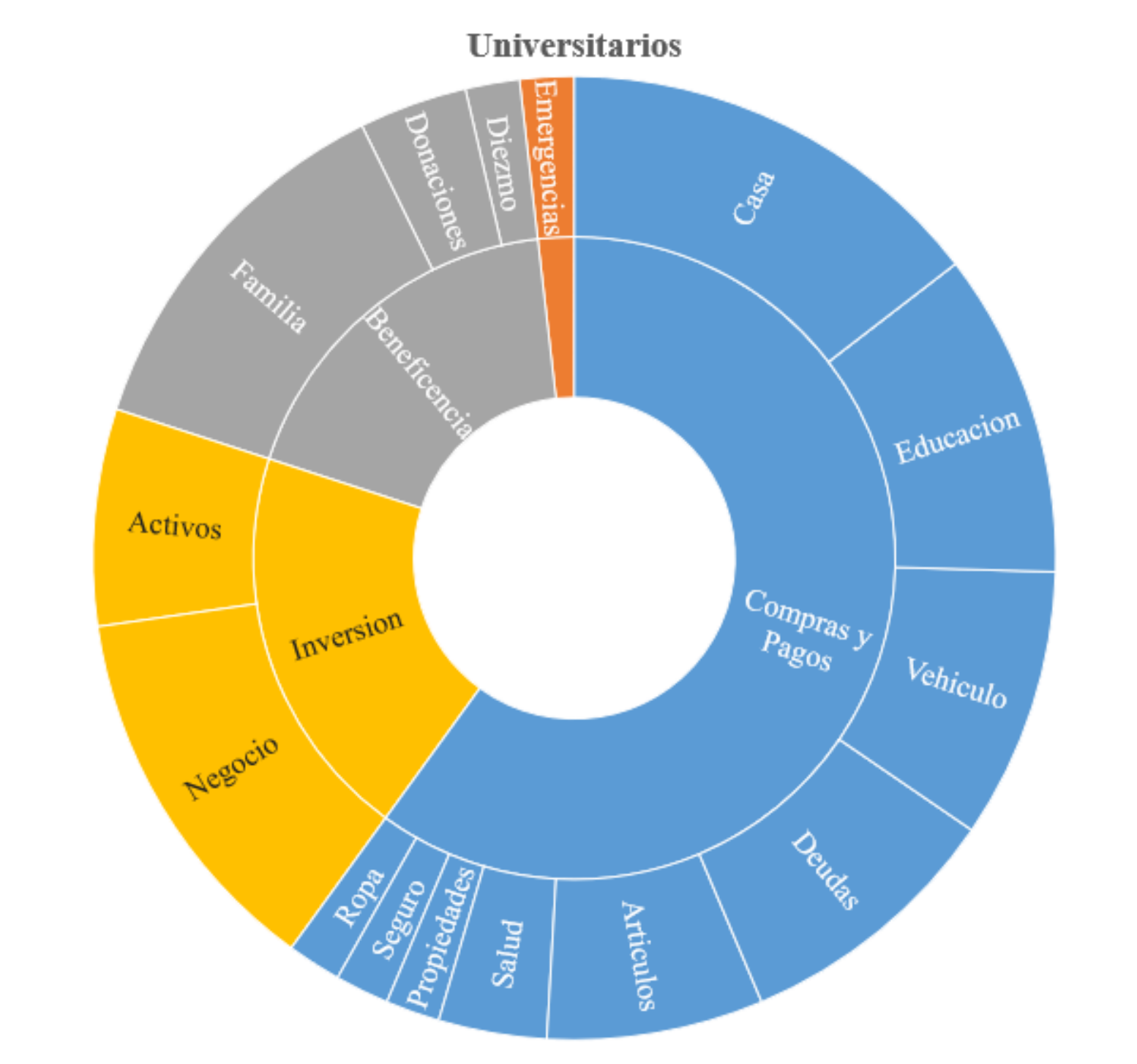

Figura 4 - Universitários

Fonte: Autoria própria

Tangram - Revista de Educação Matemática, Dourados - MS - v.2 n. 1, pp. 58 - 66 (2018) 


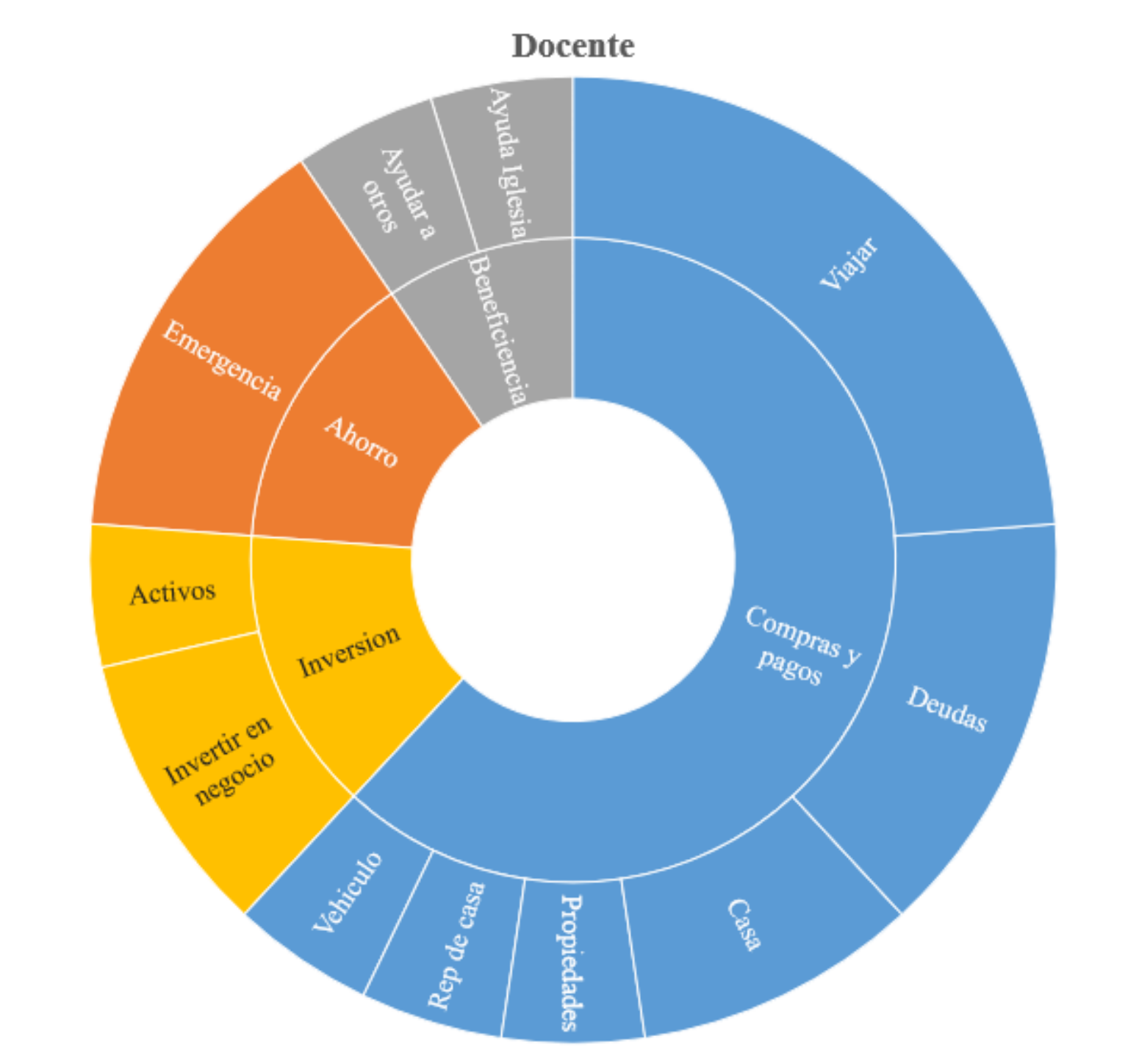

Figura 5 - Docentes

Fonte: Autoria própria

\section{Conclusiones}

Es importante generar una cultura del ahorro, en los niños, y adolescentes, pero para esto se les debe explicar cómo hacerlo y por qué o para qué hacerlo, que ahorrar no solo significa guardar dinero, sino que también debe de existir una motivación principal y se debe de crear una conciencia del valor del dinero en el tiempo.

Tangram - Revista de Educação Matemática, Dourados - MS - v.2 n. 1, pp. 58 - 66 (2018) 


\section{Una exploración de interés, ahorro e inversión estudiando una muestra poblacional de Honduras}

Los niños son agentes importantes de cambio en una sociedad, pero para que estos se destaquen positivamente deben ser educados financieramente y apegarse a los valores éticos y morales. Eliminando miedos a los riesgos financieros cuando se toman en cuenta los factores del entorno. Los niños, también pueden ahorran en bancos y recibir la retribución del interés correspondiente, al igual que hacer inversiones pequeñas que le generaren ingresos adicionales.

Existe una sociedad del consumo y endeudamiento bastante grande en los adultos, esto genera estrés y problemas médicos en la mayoría de los casos, los niños al igual que los adolescentes absorben muchos de estos factores y es por eso que muchos respondían ayudar a sus padres a pagar sus deudas y que sean más felices, o que estén más tranquilos.

Si nos educamos financieramente, tendremos ciudadanos que gocen de más tranquilidad a cualquier edad y poder alcanzar mejores estilos de vida, e incluso más saludables.

\section{Bibliografía}

Piaget, J. (1976). La contrucción de lo real en el niño. Madrid: Nueva Visión.

Piaget, J., \& Inhelder, B. (2015). De la lógica del niño a la lógica del adolescente. Madrid: Ediciones Morata.

Enviado:05/10/2018

Aceito: $10 / 12 / 2018$

Tangram - Revista de Educação Matemática, Dourados - MS - v.2 n. 1, pp. 58 - 66 (2018) 